\title{
HPV16E6-Dependent c-Fos Expression Contributes to AP-1 Complex Formation in SiHa Cells
}

\author{
Feixin Liang, ${ }^{1}$ Shinichiro Kina, ${ }^{1}$ Hiroyuki Takemoto, ${ }^{1}$ Akira Matayoshi, ${ }^{1}$ \\ Thongsavanh Phonaphonh, ${ }^{1}$ Nao Sunagawa, ${ }^{1}$ Keiichi Arakaki, ${ }^{1}$ Akira Arasaki, ${ }^{1}$ \\ Hai Kuang, ${ }^{2}$ and Hajime Sunakawa ${ }^{1}$ \\ ${ }^{1}$ Department of Clinical Neuroscience Oral and Maxillofacial Functional Rehabilitation, University of Ryukyus, \\ 207 Uehara, Nishihara, Okinawa 903-0215, Japan \\ ${ }^{2}$ Department of Oral and Maxillofacial Surgery, Guangxi Medical University, Nanning 530021, Guangxi, China
}

Correspondence should be addressed to Hajime Sunakawa, s112233@med.u-ryukyu.ac.jp

Received 9 March 2011; Revised 17 May 2011; Accepted 6 June 2011

Academic Editor: Chiara De Luca

Copyright ( 2011 Feixin Liang et al. This is an open access article distributed under the Creative Commons Attribution License, which permits unrestricted use, distribution, and reproduction in any medium, provided the original work is properly cited.

To date, the major role of HPV16E6 in cancer has been considered to be its ability to inhibit the p53 tumor-suppressor protein, thereby thwarting p53-mediated cytotoxic responses to cellular stress signals. Here, we show that HPV16E6-dependent c-fos oncogenic protein expression contributes to AP-1 complex formation under oxidative stress in SiHa cells (HPV16-positive squamous cell carcinoma of the cervix). In addition, we examined the role of HPV16E6 in TGF- $\alpha$-induced c-fos expression and found that the $\mathrm{c}$-fos protein expression induced by TGF- $\alpha$ is HPV16E6 dependent. Thus, our results provide the first evidence that HPV16E6 contributes to AP-1 complex formation after both ligand-dependent and independent EGFR activation, suggesting a new therapeutic approach to the treatment of HPV-associated tumors.

\section{Introduction}

HPV (human papillomavirus) infection is a hallmark of uterine cervical cancer and is thought to be important, if not causal, for some types of tumorigenesis [1-3]. Two HPVencoded proteins, E6 and E7, inactivate and inhibit the expression of the p53 and RB tumor suppressor proteins, respectively. Nevertheless, HPV infection is not sufficient for tumorigenesis, because HPV infection is also present in healthy individuals [4], and the overexpression of E6/E7 alone is capable of immortalizing primary human epithelial cells but does not induce tumor cell transformation [5]. Thus, understanding the conditions that stimulate HPVinfected cells is crucial for the development of effective treatments for HPV-associated tumors.

The transcription factor AP-1, which is composed of heterodimers of members of the c-Jun and c-Fos families, regulates various cellular processes such as enhanced proliferation, apoptosis, and tumor metastasis [6]. In particular, among the various members of the AP-1 family, c-fos acts as a tumor promoter, and c-fos upregulation causes cellular transformation that is characterized by colony formation in soft-agar and tumor formation in nude mice $[7,8]$. In addition, when c-fos binds to c-jun, it increases the gene expression of cyclinD1 and contributes to the potentiation of malignancy [9-11].

In cervical cancer, the AP-1 complex formed during tumor development consists of a c-fos/c-jun heterodimer $[9,12-14]$, and c-fos/c-jun formation is also implicated in HPV-induced esophageal tumor development [15]. In fact, various c-fos target genes are reported to be expressed at higher levels in cervical cancer cells with comparison to normal cervical epithelial cells [16]. While c-fos showed very low expression in normal samples and moderate expression in cervical premalignant lesions, the tumor tissues showed very strong expression [13]. It is, therefore, reasonable to assume that $\mathrm{c}$-fos regulation plays a fundamental role in $\mathrm{HPV}$-induced tumor development. However, the extracellular conditions in which c-fos expression and AP-1 complex formation are induced in HPV-infected cells are unknown. 
A shift in the composition of AP-1 from fra-1/c-jun to c-fos/c-jun heterodimers occurs during HPV-infected tumor development $[7,14]$. The same shift in AP-1 composition also takes place under oxidative stress, such as after UV-B exposure [10]. As transient transfection experiments showed that HPV16E6 induces the transcription of the c-fos promoter [17], we hypothesized that under oxidative stress HPV16E6 function might contribute to c-fos expression and c-fos/c-jun heterodimer formation.

There are at least 15 cancer-associated HPV types, and of these, HPV16 is found in more than 50\% of HPV-positive cancer tissues $[1,2]$. Here, we used SiHa cells (HPV16positive squamous cell carcinoma of the cervix) and showed that $\mathrm{H}_{2} \mathrm{O}_{2}$ and TGF- $\alpha$, which are promoters of the multistep carcinogenic process $[18,19]$, induced $c$-fos/c-jun heterodimer formation in $\mathrm{SiHa}$ cells, whereas o-phenanthroline inhibited $\mathrm{H}_{2} \mathrm{O}_{2}$-induced c-fos upregulation. $\mathrm{H}_{2} \mathrm{O}_{2}$ and TGF$\alpha$-induced c-fos upregulation was impaired in SiHa cells transfected with siRNA HPV16E6. This result further implicates $\mathrm{H}_{2} \mathrm{O}_{2}$ and TGF- $\alpha$ signaling in the pathogenesis of HPVinduced tumor development.

\section{Material and Methods}

2.1. Reagents. $\mathrm{H}_{2} \mathrm{O}_{2}$ was purchased from WAKO (Tokyo, Japan), and $o$-phenanthroline was obtained from SigmaAldrich (S.t. Louis, Mo, USA).

2.2. Cell Culture and Treatment. The SiHa and Caski cell line used in our study was obtained from the American Type Culture Collection. SiHa cells were routinely cultured in DMEM (Invitrogen) supplemented with 5\% fetal bovine serum (Sigma) at $37^{\circ} \mathrm{C}$ under $5 \% \mathrm{CO}_{2}$. SiHa cells were serum-deprived for at least 16 hours before being stimulated with $\mathrm{H}_{2} \mathrm{O}_{2}(1 \mathrm{mM})$. To observe the effect of an $\mathrm{Fe}^{2+}$ chelating agent on the activation of c-fos, $o$-phenanthroline $(0.2 \mathrm{mM})$ was added to the culture medium 1 hour before stimulation with $\mathrm{H}_{2} \mathrm{O}_{2}$.

2.3. SDS-PAGE and Western Blotting. The cell cultures (80$100 \%$ confluent) were washed twice with ice-cold phosphate buffered saline and lysed in $1 \times$ Laemmli sample buffer supplemented with a protease inhibitor cocktail (Roche) and a phosphatase inhibitor cocktail (Roche). The cells were scraped and homogenized at $4^{\circ} \mathrm{C}$ with a syringe and a thin needle, and the cell lysates were subjected to sodium dodecyl sulfate-polyacrylamide gel electrophoresis (SDS-PAGE, 10\% resolving gel). The resultant proteins were electrophoretically transferred onto nitrocellulose membranes (Pall Corporation), before being incubated for $2 \mathrm{~h}$ at room temperature with blocking buffer containing $4 \%$ nonfat dried milk in TBS (20 mM Tris (pH 7.6) and $150 \mathrm{mM} \mathrm{NaCl}$ ). They were then washed with TBS-T $(0.1 \%$ Tween-20) and incubated overnight at $4{ }^{\circ} \mathrm{C}$ in TBS buffer containing $4 \%$ BSA (Wako) and appropriate antibodies. The antibodies used in the experiment were anti-c-fos (Santa Cruz, sc-52, 1:500) and anti-c-jun (Cell Signaling, L70B11, 1:500), and the secondary antibodies were Donkey Antirabbit IgG/HRP
(Amersham NA934, 1:5000) and Goat Antimouse IgG/HRP (Chemicon, AP124P 1:5000).

The protein bands were visualized using an enhanced chemiluminescence (ECL) detection system (GE Healthcare Bio-Sciences). The signals from the membrane were detected and imaged using a LAS-4000 imager (Fujifilm Corporation). The membranes were then stripped $\left(30 \mathrm{~min}\right.$ at $\left.56^{\circ} \mathrm{C}\right)$ in stripping buffer containing $100 \mathrm{mM}$ 2-mercaptoethanol, $2 \%$ SDS, and $62.5 \mathrm{mM}$ Tris- $\mathrm{HCl}(\mathrm{pH}$ 6.7) and reprobed with $\beta$-actin or tubulin as a loading control. All Western blots were performed at least three times for each experiment. To quantify the Western blot data, densitometric analysis of ECL-exposed blots was performed using the NIH ImageJ software (version 1.45f).

2.4. CoIP Assay. The antibodies used for the Western blot analysis were c-Fos, $c-J u n$, and $\mathrm{CBP} / \beta$. For the c-Fos coIP assay, $\mathrm{SiHa}$ cells were lysed in a modified RIPA buffer $(50 \mathrm{mM}$ Tris- $\mathrm{HCl}$ ( $\mathrm{pH} 7.4$ ), $150 \mathrm{mM} \mathrm{NaCl}, 1 \mathrm{mM}$ EDTA, and $1 \%$ NP-40) and a protease inhibitor mixture (Roche). CoIP was performed using $2 \mu \mathrm{g}$ of the c-Fos antibody or the respective isotype control.

2.5. Preparation of Small Interfering RNA and Transfection. Synthesized siRNA duplexes were obtained from Invitrogen. The siRNA sequences targeting HPV16E6 corresponded to nucleotides $5^{\prime}$-ACCGUUGUGUGAUUUGUUATT-3' (siRNA1-HPV16E6) and 5'-UAACAAAUCACACAACGGUTT-3' (siRNA2-HPV16E6) of the coding region [20]. The sequence of the negative control (siRNA-scrambled) was as follows: $5^{\prime}$-CCAUUCCGAUCCUGAUCCGTT- $3^{\prime}$ and $5^{\prime}-$ CGGAUCAGGAUCGGAAUGGTT- $3^{\prime}$. Cells in the exponential growth phase were plated in a $35 \mathrm{~mm}$ dish containing antibiotic-free medium at 30\% confluence and then transfected with siRNA (siRNA-HPV16E6 or siRNA-scrambled) using Oligofectamine (Invitrogen) and Opti-MEM I (Invitrogen), according to the manufacturer's protocol. Silencing was examined $24 \mathrm{~h}$ after transfection.

2.6. RT-PCR. Total RNA were extracted from the harvested cells using Isogen (Nippon Gene). After the removal of genomic DNA, approximately $1 \mu \mathrm{g}$ of RNA was used to generate cDNA using Reverse Transcriptase M-MLV (RNase $\mathrm{H}-$ ) (TaKaRa) and random hexamers (Fermentas). The primer sequences used were as follows: $5^{\prime}$ CGGAATTCATGCACCAAAAGCGAAC-3' (sense) and 5' CCCAAGCTTACAGCTGGGTTTCTCT- $3^{\prime}$ (antisense) for HPV16E6 [21] and 5'-CAGGGCTGCTTTTAACTCTG-3' (sense) and $5^{\prime}$-GATGATCTTGAGGCTGTTGTC-3' (antisense) for GAPDH. The PCR reactions for HPV16E6 were run for 30 cycles. GAPDH amplification products were used as a loading control. All amplification products were separated in $2 \%$ agarose gels. All RT-PCR were performed at least three times for each experiment.

2.7. Statistical Analysis. Data are expressed as the mean \pm s.e.m. The paired-sample $t$-test was performed for statistical comparisons. For all tests, a $P$ value of less than 0.05 was considered to be significant. 
(h)

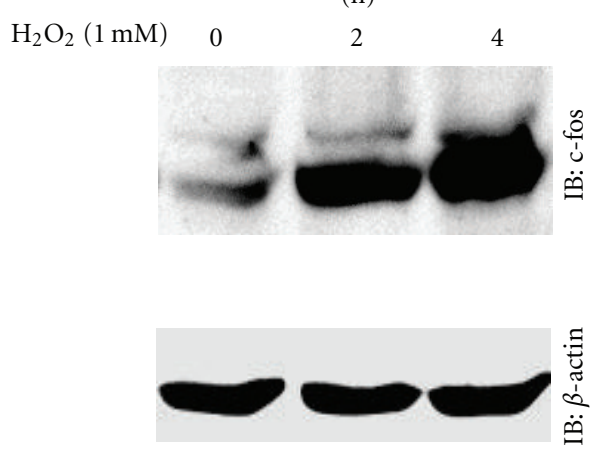

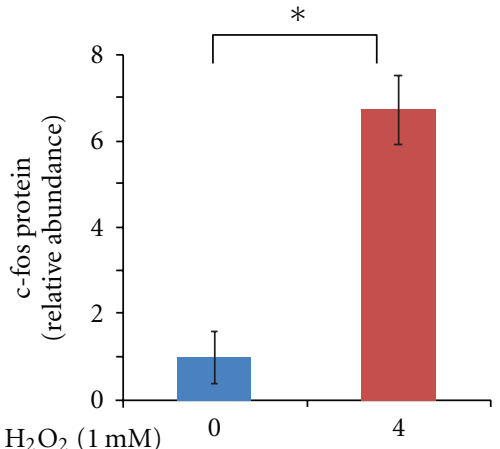

(h)

$*$

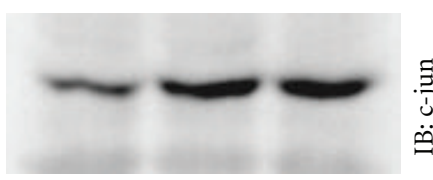

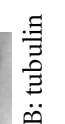

(1)

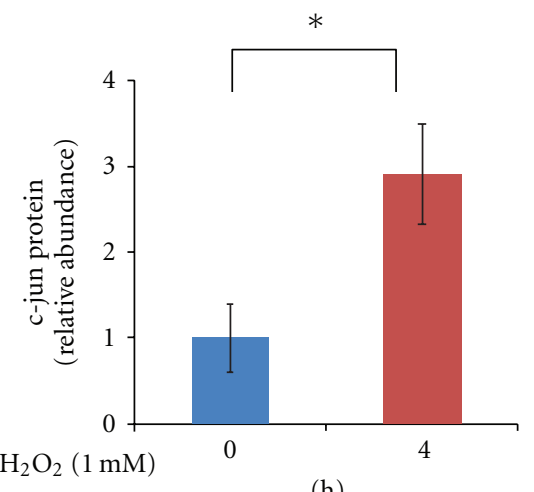

(h)

(h)

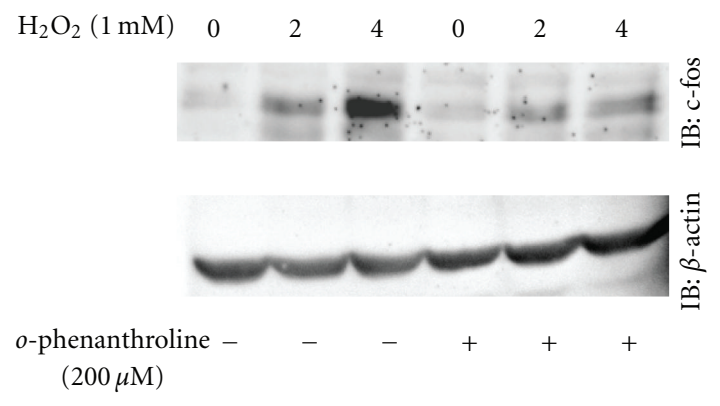

(a)

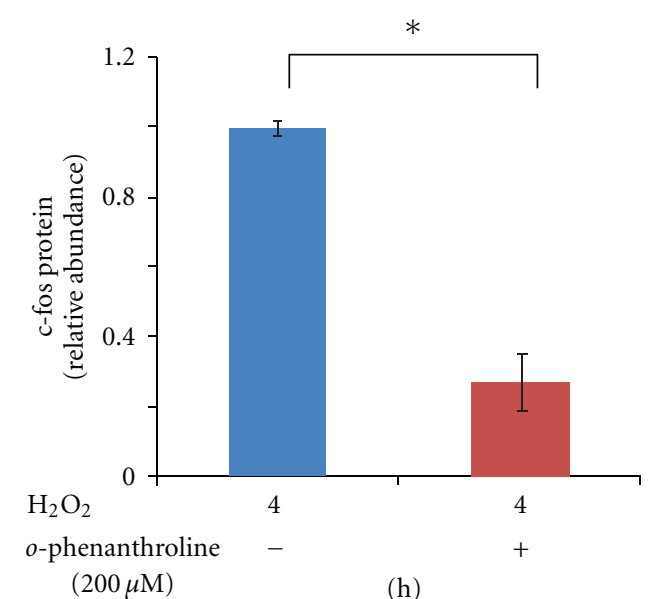

$(200 \mu \mathrm{M})$

(h)

(b)

FIGURE 1: (a) Upregulation of AP-1 gene expression in SiHa cells at the indicated time points after $\mathrm{H}_{2} \mathrm{O}_{2}(1 \mathrm{mM})$ exposure. Representative blots are shown and include $\beta$-actin or tubulin as a loading control, along with the results of densitometric analysis $(0 \mathrm{~h}, 4 \mathrm{~h}$; normalized to $\beta$-actin or tubulin). ${ }^{*} P<0.05, n=3$. (b) Inhibitory effect of $o$-phenanthroline on $\mathrm{H}_{2} \mathrm{O}_{2}$-induced c-fos upregulation. Cells were pretreated for 1 hour with or without $o$-phenanthroline $(200 \mu \mathrm{M})$ before $\mathrm{H}_{2} \mathrm{O}_{2}(1 \mathrm{mM})$ exposure. Representative blots are shown and include $\beta$-actin as a loading control, along with the results of densitometric analysis ( $4 \mathrm{~h}$; normalized to $\beta$-actin). ${ }^{*} P<0.05, n=4$.

\section{Results}

3.1. o-phenanthroline Inhibits $\mathrm{H}_{2} \mathrm{O}_{2}$-Induced c-Fos Expression. The upregulation of c-fos has been observed after $\mathrm{H}_{2} \mathrm{O}_{2}$ treatment in both epithelial and endothelial cells $[19,22]$, which raises the possibility that $\mathrm{SiHa}$ cells might respond to $\mathrm{H}_{2} \mathrm{O}_{2}$ in a similar manner. To test this, we analyzed c-fos protein expression after $\mathrm{H}_{2} \mathrm{O}_{2}$ treatment in $\mathrm{SiHa}$ cells. Western blotting analysis revealed aberrantly high levels of c-fos protein expression after $\mathrm{H}_{2} \mathrm{O}_{2}$ treatment (Figure 1(a)). In the $\mathrm{H}_{2} \mathrm{O}_{2}$-treated $\mathrm{SiHa}$ cells, the expression of the AP1 family member c-jun was also upregulated (Figure 1(a)). $o$-phenanthroline is an iron chelator [23] that protects cells from cancer progression by inhibiting the Fenton reaction, 
(h)

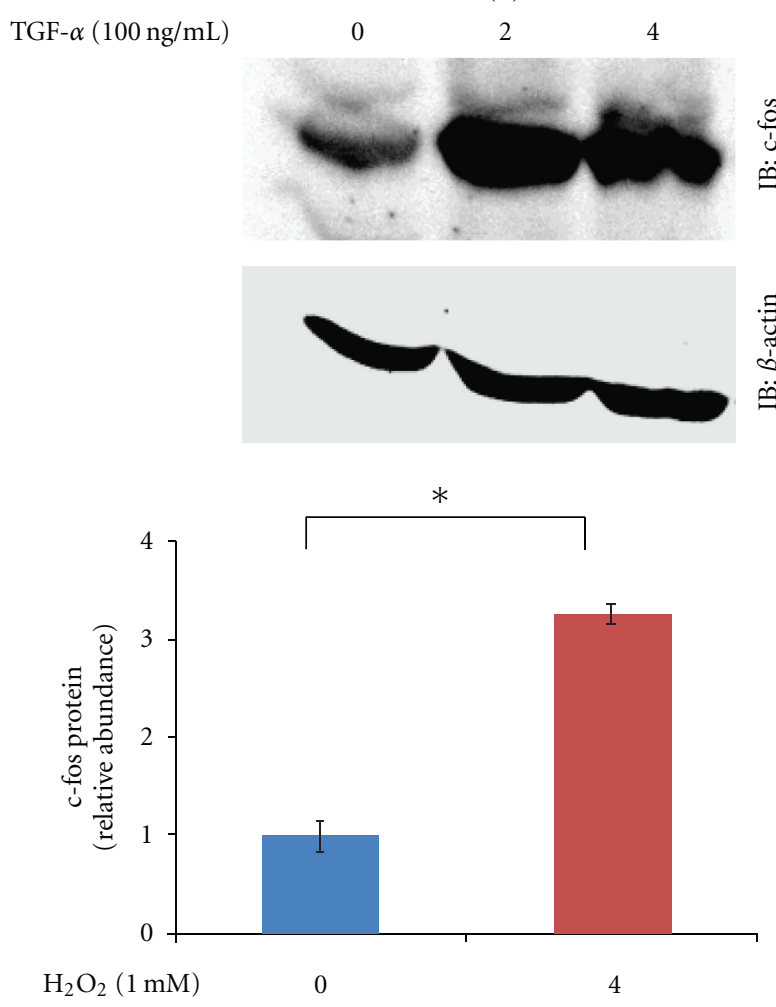

(h)

(a)

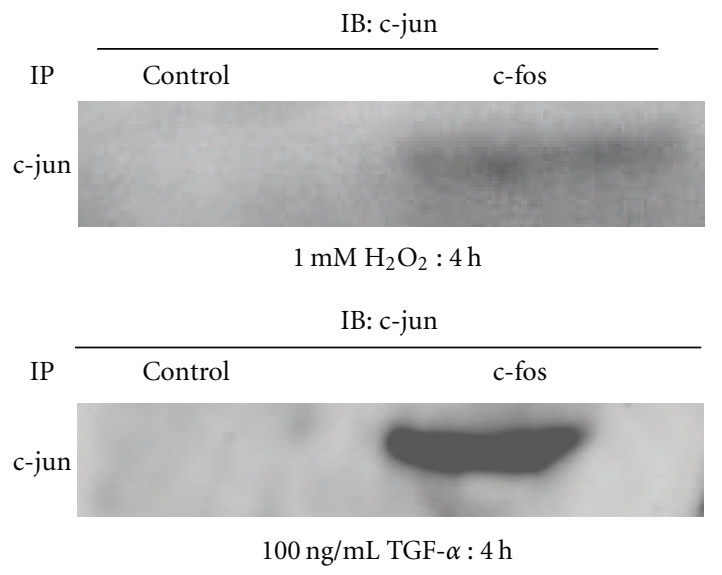

(b)

Figure 2: (a) c-fos upregulation in SiHa cells after TGF- $\alpha(100 \mathrm{ng} / \mathrm{mL})$ treatment. Cells were harvested at the indicated time points and used for Western blotting analysis. Representative blots are shown and include $\beta$-actin as a loading control, along with the results of densitometric analysis ( 0 h, 4 h; normalized to $\beta$-actin). ${ }^{*} P<0.01, n=3$. (b) IP of c-fos was performed using whole-cell extracts. Coprecipitated proteins were detected by Western blotting analysis using antibodies specific to c-jun.

and it has been reported that in a mouse model of gastric cancer the intraperitoneal injection of $o$-phenanthroline significantly reduced the incidence of gastric cancers [24] by inhibiting the Fenton reaction. The effect of $o$-phenanthroline on c-fos expression in SiHa cells is unclear; therefore, we tested the effect of $o$-phenanthroline on $\mathrm{H}_{2} \mathrm{O}_{2}$-induced cfos expression in $\mathrm{SiHa}$ cells by pre-treating $\mathrm{SiHa}$ cells with $o$ phenanthroline before $\mathrm{H}_{2} \mathrm{O}_{2}$ treatment. As a result, we found that $o$-phenanthroline markedly inhibited $\mathrm{H}_{2} \mathrm{O}_{2}$-induced cfos expression (Figure 1(b)).

\subsection{Characterization of $c$-Fos/c-jun Heterodimers after Ligand} -Dependent and Independent EGFR Activation. The upregulation of c-fos observed in epithelial cells after $\mathrm{H}_{2} \mathrm{O}_{2}$ treatment is mainly mediated through EGFR activation [18]. We, therefore, examined c-fos protein expression in $\mathrm{SiHa}$ cells that had been treated with the EGFR ligand TGF- $\alpha$. Western blotting analysis revealed aberrantly high levels of c-fos protein expression after TGF- $\alpha$ treatment (Figure 2(a)). We then investigated c-fos/c-jun heterodimer formation in $\mathrm{SiHa}$ cells. We stimulated SiHa cells with $\mathrm{H}_{2} \mathrm{O}_{2}$ or TGF- $\alpha$ for 4 hours, immunoprecipitated c-fos, and determined its partner AP-1 family member by Western blotting (Figure 2(b)). Interactions between $\mathrm{c}$-fos and c-jun were observed after both $\mathrm{H}_{2} \mathrm{O}_{2}$ and TGF- $\alpha$ stimulation (Figure 2(b): the IP with isotype control did not show any specific band).

3.3. HPV16E6 Mediates $\mathrm{H}_{2} \mathrm{O}_{2}$ and TGF- $\alpha$-Induced c-Fos Expression. We next tested whether HPV16E6 is necessary for the $c$-fos expression induced by $\mathrm{H}_{2} \mathrm{O}_{2}$ or TGF- $\alpha$ treatment. To directly address the role of HPV16E6 protein in c-fos expression, we transfected SiHa cells with siRNA HPV16E6 (Figure 3(a)). A scrambled nonspecific siRNA duplex was used as a negative control. We observed siRNA HPV16E6dependent reductions in $\mathrm{H}_{2} \mathrm{O}_{2}$ and TGF- $\alpha$ induced $c$-fos expression (Figures 3(b) and 3(c)). Similar results that siRNA HPV16E6-dependent reduction in c-fos expression induced by $\mathrm{H}_{2} \mathrm{O}_{2}$ treatment were obtained in another cervical cancer cell line, Caski cell (Figure 3(d)). These data suggest that HPV16E6 is necessary for $\mathrm{H}_{2} \mathrm{O}_{2}$ and TGF- $\alpha$ induced-c-fos expression.

\section{Discussion}

Our findings provide new insights into the mechanism of c-fos/c-jun heterodimer formation during the development of cervical cancer. First, our findings show that c-fos/cjun heterodimer formation results from both $\mathrm{H}_{2} \mathrm{O}_{2}$ and 


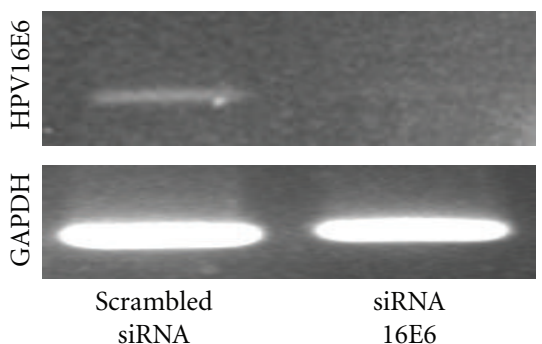

(a)
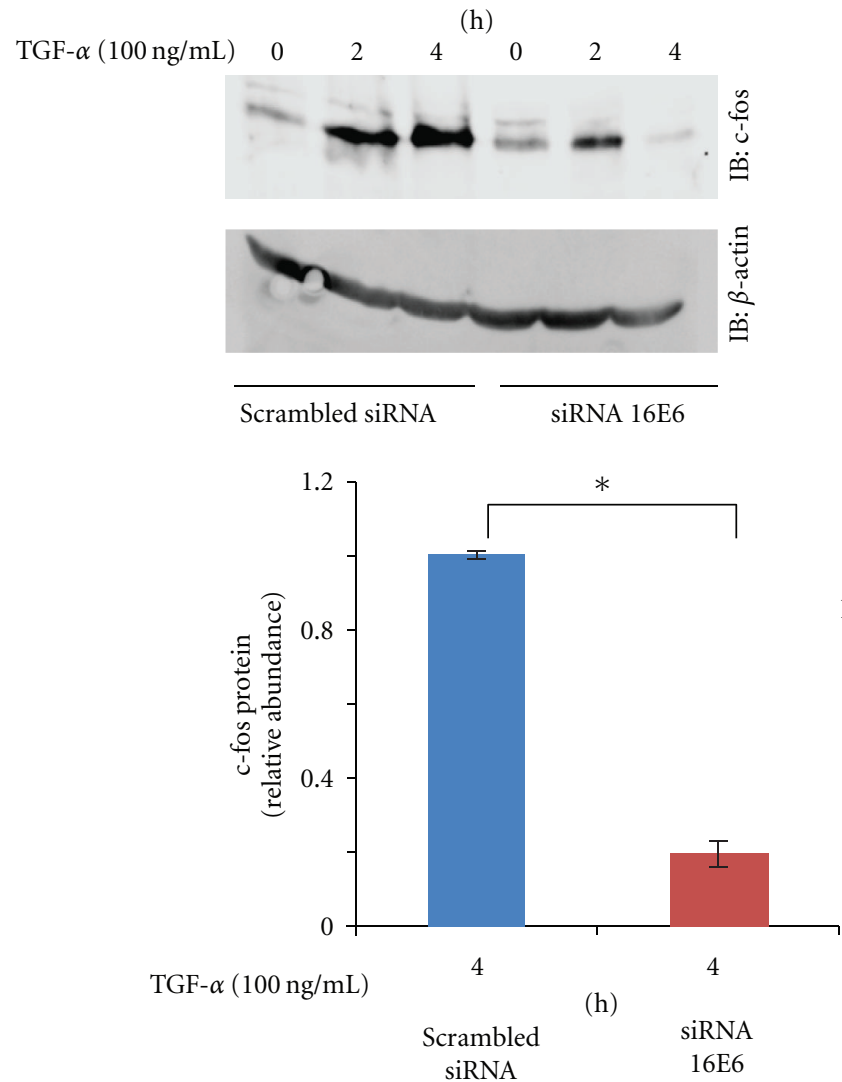

(h)

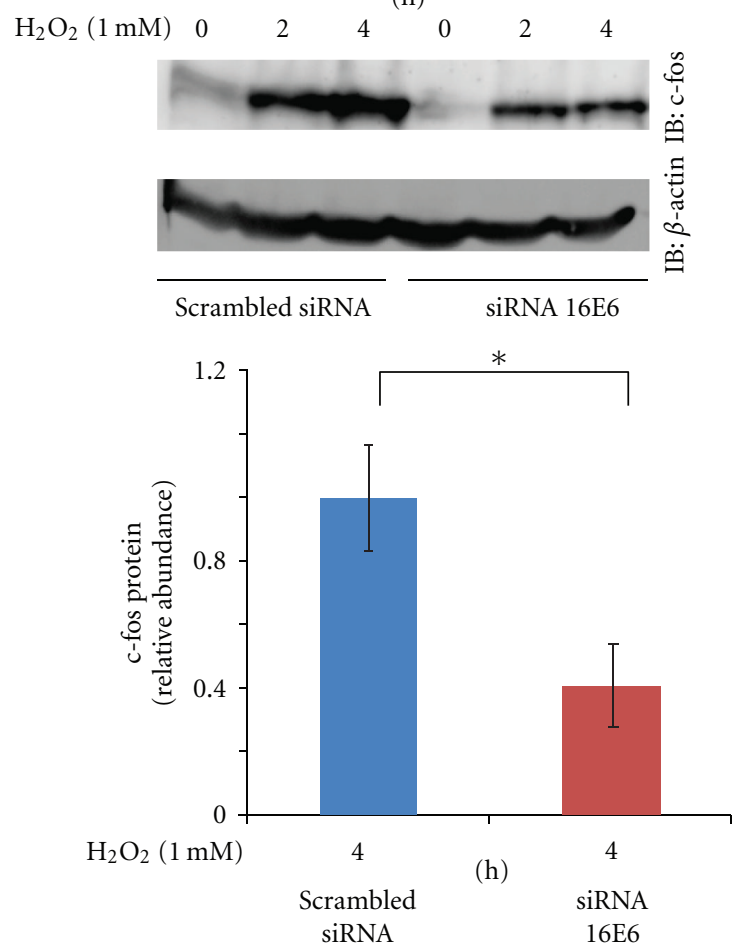

(b)

(h)
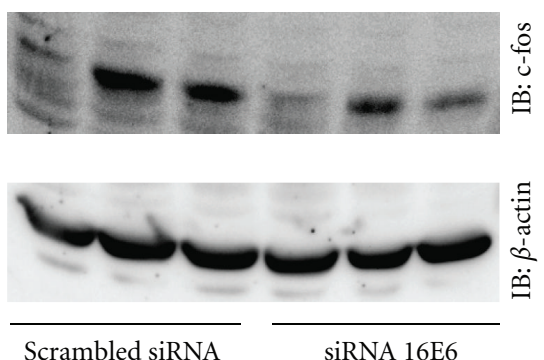

(d)

(c)

FIGURE 3: HPV16E6-mediated upregulation of c-fos in SiHa cells. (a) The mRNA levels of HPV16E6 were detected by RT-PCR after HPV16E6 siRNA transfection into SiHa cells. Cells were transfected with scrambled siRNA or HPV16E6 siRNA for 24 hours. (b) HPV16E6mediated upregulation of c-fos expression in SiHa cells after $\mathrm{H}_{2} \mathrm{O}_{2}$ exposure. The transfected cells were exposed to $\mathrm{H}_{2} \mathrm{O}_{2}(1 \mathrm{mM})$ and harvested at the indicated time points, before being subjected to Western blotting analysis. Representative blots are shown and include $\beta$-actin as a loading control, along with the results of densitometric analysis ( $4 \mathrm{~h}$; normalized to $\beta$-actin). ${ }^{*} P<0.05, n=4$. (c) HPV16E6-mediated upregulation of c-fos expression in SiHa cells after TGF- $\alpha$ exposure. Transfected cells were exposed to TGF- $\alpha$ ( $100 \mathrm{ng} / \mathrm{mL})$ and harvested at the indicated time points, before being subjected to Western blotting analysis. Representative blots are shown and include $\beta$-actin as a loading control, along with the results of densitometric analysis ( $4 \mathrm{~h}$; normalized to $\beta$-actin). ${ }^{*} P<0.05, n=4$. (d) HPV16E6-mediated upregulation of c-fos expression in Caski cells after $\mathrm{H}_{2} \mathrm{O}_{2}$ exposure. The transfected cells were exposed to $\mathrm{H}_{2} \mathrm{O}_{2}(1 \mathrm{mM})$ and harvested at the indicated time points, before being subjected to Western blotting analysis.

TGF- $\alpha$ stimulation. The current view is that in cervical cancer $\mathrm{c}$-fos/c-jun heterodimer formation results from the inefficient expression of the ternary complex factor Net [25], but the evidence we have uncovered for HPV16E6 dependent c-fos expression after $\mathrm{H}_{2} \mathrm{O}_{2}$ or TGF- $\alpha$ stimulation broadens the scope of the mechanisms of $\mathrm{c}$-fos/c-jun heterodimer formation in extracellular conditions such as oxidative stress. For example, the observed shift in AP-1 composition from fra-1/c-jun to c-fos/c-jun heterodimers in HaCaT keratinocytes after UV-B exposure [10] suggests that after being 
induced by extracellular and environmental stimuli, c-fos expression and c-fos/c-jun heterodimer formation contribute to the pathological process of HPV positive skin cancer. Therefore, studies of c-fos expression, HPV infection, and skin tumor development are necessary.

Second, our data indicate that HPV16E6 is necessary and sufficient for $\mathrm{c}$-fos/c-jun heterodimer formation to occur in $\mathrm{SiHa}$ cells under both $\mathrm{H}_{2} \mathrm{O}_{2}$ and TGF- $\alpha$ stimulation. In the presence of transition metals such as iron and copper, $\mathrm{H}_{2} \mathrm{O}_{2}$ can be oxidized into extremely reactive and toxic $\mathrm{HO} \bullet$ via the Fenton reaction. The hydroxyl radical $(\mathrm{HO} \bullet)$ then activates EGFR [26]. Our data show that $\mathrm{H}_{2} \mathrm{O}_{2}$ and TGF- $\alpha$ are stimulators of $\mathrm{c}$-fos/c-jun heterodimer formation and confirm that the iron chelator is an inhibitor of c-fos expression that acts by inhibiting the Fenton reaction. The negative effect of $o$-phenanthroline on HPV16E6 mediated c-fos expression might explain why iron chelation inhibits growth and induces the apoptosis of HPV-positive carcinoma cells [27]. Tumorigenic cervical cells express higher levels of intracellular iron [28], which creates an environment that favors HPV16E6-mediated c-fos/c-jun heterodimer formation in HPV-infected cells. This implies that iron is necessary for c-fos/c-jun heterodimer formation. The precise triggers of $\mathrm{H}_{2} \mathrm{O}_{2}$ expression around cervical epithelial cells are unknown, but it has been proposed that chronic inflammation triggers the accumulation of macrophages in the vicinity of the cervix, and that these cells subsequently produce the antimicrobial molecule $\mathrm{H}_{2} \mathrm{O}_{2}$.

Finally, our data indicate that cervical cancer, the hallmark of which is HPV infection, is an EGFR-sensitive disease regardless of ligand-dependent or ligand-independent stimulation. EGFR mAb therapies are effective for treating squamous cell carcinoma of the head and neck and are also being evaluated in other HPV-associated tumors [29]. One of the best-known mechanisms of EGFR mAb therapy resistance is ligand-independent EGFR activation [30]. This was observed in studies of squamous carcinoma cells (T-Hep3) that naturally overexpress the uPA receptor, one of which found that EGFR was activated by the uPA receptor in a ligand-independent fashion, resulting in resistance to EGFR $\mathrm{mAb}$ [31]. Therapies such as the use of $o$-phenanthroline, or alternative approaches such as the use of small molecule EGFR tyrosine kinase inhibitors that block the intracellular tyrosine kinase domain, could hold great potential for the treatment of head and neck cancer.

\section{References}

[1] R. Zelkowitz, "Cancer: HPV casts a wider shadow," Science, vol. 323, no. 5914, pp. 580-581, 2009.

[2] X. Wang, X. Tian, F. Liu et al., "Detection of HPV DNA in esophageal cancer specimens from different regions and ethnic groups: a descriptive study," BMC Cancer, vol. 10, article no. 19, 2010.

[3] B. Akgül, J. C. Cooke, and A. Storey, "HPV-associated skin disease," Journal of Pathology, vol. 208, no. 2, pp. 165-175, 2006.

[4] P. R. do Sacramento, E. Babeto, J. Colombo et al., "The prevalence of human papillomavirus in the oropharynx in healthy individuals in a Brazilian population," Journal of Medical Virology, vol. 78, no. 5, pp. 614-618, 2006.

[5] A. E. Al Moustafa, W. D. Foulkes, A. Wong et al., "Cyclin D1 is essential for neoplastic transformation induced by both E6/E7 and E6/E7/ErbB-2 cooperation in normal cells," Oncogene, vol. 23, no. 30, pp. 5252-5256, 2004.

[6] R. Eferl and E. F. Wagner, "AP-1: a double-edged sword in tumorigenesis," Nature Reviews Cancer, vol. 3, no. 11, pp. 859$868,2003$.

[7] U. Soto, B. C. Das, M. Lengert, P. Finzer, H. Zur Hausen, and F. Rösl, "Conversion of HPV 18 positive non-tumorigenic HeLafibroblast hybrids to invasive growth involves loss of TNF- $\alpha$ mediated repression of viral transcription and modification of the AP-1 transcription complex," Oncogene, vol. 18, no. 21, pp. 3187-3198, 1999.

[8] A. Joo, H. Aburatani, E. Morii, H. Iba, and A. Yoshimura, "STAT3 and MITF cooperatively induce cellular transformation through upregulation of c-fos expression," Oncogene, vol. 23, no. 3, pp. 726-734, 2004.

[9] E. Turatti, A. da Costa Neves, M. H. de Magalhães, and S. O. de Sousa, "Assessment of c-Jun, c-Fos and cyclin D1 in premalignant and malignant oral lesions," Journal of oral science, vol. 47, no. 2, pp. 71-76, 2005.

[10] M. V. Catani, I. Savini, A. Rossi, G. Melino, and L. Avigliano, "Biological role of vitamin C in keratinocytes," Nutrition Reviews, vol. 63, no. 3, pp. 81-90, 2005.

[11] S. J. Cooper, J. MacGowan, J. Ranger-Moore, M. R. Young, N. H. Colburn, and G. T. Bowden, "Expression of dominant negative c-jun inhibits ultraviolet B-induced squamous cell carcinoma number and size in an SKH-1 hairless mouse model," Molecular Cancer Research, vol. 1, no. 11, pp. 848-854, 2003.

[12] J. De Wilde, J. De-Castro Arce, P. J. F. Snijders, C. J. L. M. Meijer, F. Rösl, and R. D. M. Steenbergen, "Alterations in AP-1 and AP-1 regulatory genes during HPV-induced carcinogenesis," Cellular Oncology, vol. 30, no. 1, pp. 77-87, 2008.

[13] B. K. Prusty and B. C. Das, "Constitutive activation of transcription factor AP-1 in cervical cancer and suppression of human papillomavirus (HPV) transcription and AP-1 activity in HeLa cells by curcumin," International Journal of Cancer, vol. 113, no. 6, pp. 951-960, 2005.

[14] U. Soto, C. Denk, P. Finzer, K. J. Hutter, H. Zur Hausen, and F. Rösl, "Genetic complementation to non-tumorigenicity in cervical-carcinoma cells correlates with alterations in AP-1 composition," International Journal of Cancer, vol. 86, no. 6, pp. 811-817, 2000.

[15] S. Hussain, A. C. Bharti, I. Salam et al., "Transcription factor AP-1 in esophageal squamous cell carcinoma: alterations in activity and expression during human papillomavirus infection,” BMC Cancer, vol. 9, article no. 329, 2009.

[16] T. Rajkumar, K. Sabitha, N. Vijayalakshmi et al., "Identification and validation of genes involved in cervical tumourigenesis," BMC Cancer, vol. 11, article 80, 2011.

[17] A. Morosov, W. C. Phelps, and P. Raychaudhuri, "Activation of the $\mathrm{c}$-fos gene by the HPV16 oncoproteins depends upon the cAMP-response element at -60," Journal of Biological Chemistry, vol. 269, no. 28, pp. 18434-18440, 1994.

[18] S. Kina, T. Nakasone, H. Takemoto et al., "Regulation of chemokine production via oxidative pathway in HeLa cells," Mediators of Inflammation, vol. 2009, Article ID 183760, 5 pages, 2009.

[19] R. P. Huang, A. Peng, A. Golard et al., "Hydrogen peroxide promotes transformation of rat liver non-neoplastic epithelial cells through activation of epidermal growth factor receptor," Molecular Carcinogenesis, vol. 30, no. 4, pp. 209-217, 2001. 
[20] J. An, D. Mo, H. Liu et al., "Inactivation of the CYLD deubiquitinase by HPV E6 mediates hypoxia-induced NF- $\kappa \mathrm{B}$ activation," Cancer Cell, vol. 14, no. 5, pp. 394-407, 2008.

[21] C. L. Au Yeung, T. Y. Tsang, P. L. Yau, and T. T. Kwok, "Human papillomavirus type $16 \mathrm{E} 6$ induces cervical cancer cell migration through the p53/microRNA-23b/urokinase-type plasminogen activator pathway," Oncogene, vol. 30, no. 21, pp. 2401-2410, 2011.

[22] T. Ichiki, T. Tokunou, K. Fukuyama, N. Iino, S. Masuda, and A. Takeshita, "Cyclic AMP response element-binding protein mediates reactive oxygen species-induced c-fos expression," Hypertension, vol. 42, no. 2, pp. 177-183, 2003.

[23] K. Z. Guyton, Y. Liu, M. Gorospe, Q. Xu, and N. J. Holbrook, "Activation of mitogen-activated protein kinase by $\mathrm{H} 2 \mathrm{O} 2$ : role in cell survival following oxidant injury," Journal of Biological Chemistry, vol. 271, no. 8, pp. 4138-4142, 1996.

[24] M. Tatsuta, H. Iishi, M. Baba et al., "Suppression by iron chelator phenanthroline of sodium chloride-enhanced gastric carcinogenesis induced by $\mathrm{N}$-methyl-N'-nitro-N-nitrosoguanidine in Wistar rats," Cancer Letters, vol. 191, no. 1, pp. 9-16, 2003.

[25] J. Van Riggelen, G. Buchwalter, U. Soto et al., "Loss of net as repressor leads to constitutive increased c-fos transcription in cervical cancer cells," Journal of Biological Chemistry, vol. 280, no. 5, pp. 3286-3294, 2005.

[26] Y. R. Helfrich, D. L. Sachs, and J. J. Voorhees, "The biology of skin aging," US Dermatology, vol. 4, no. 1, pp. 48-51, 2009.

[27] T. Simonart, J. R. Boelaert, R. Mosselmans et al., "Antiproliferative and apoptotic effects of iron chelators on human cervical carcinoma cells," Gynecologic Oncology, vol. 85, no. 1, pp. 95102, 2002.

[28] G. L. Disbrow, A. C. Baege, K. A. Kierpiec et al., "Dihydroartemisinin is cytotoxic to papillomavirus-expressing epithelial cells in vitro and in vivo," Cancer Research, vol. 65, no. 23, pp. 10854-10861, 2005.

[29] J. B. Vermorken, R. Mesia, F. Rivera et al., "Platinum-based chemotherapy plus cetuximab in head and neck cancer," New England Journal of Medicine, vol. 359, no. 11, pp. 1116-1127, 2008.

[30] E. R. Camp, J. Summy, T. W. Bauer, W. Liu, G. E. Gallick, and L. M. Ellis, "Molecular mechanisms of resistance to therapies targeting the epidermal growth factor receptor," Clinical Cancer Research, vol. 11, no. 1, pp. 397-405, 2005.

[31] D. Liu, J. A. Aguirre Ghiso, Y. Estrada, and L. Ossowski, "EGFR is a transducer of the urokinase receptor initiated signal that is required for in vivo growth of a human carcinoma," Cancer Cell, vol. 1, no. 5, pp. 445-457, 2002. 


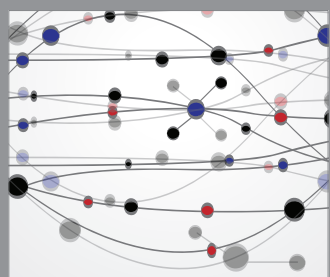

The Scientific World Journal
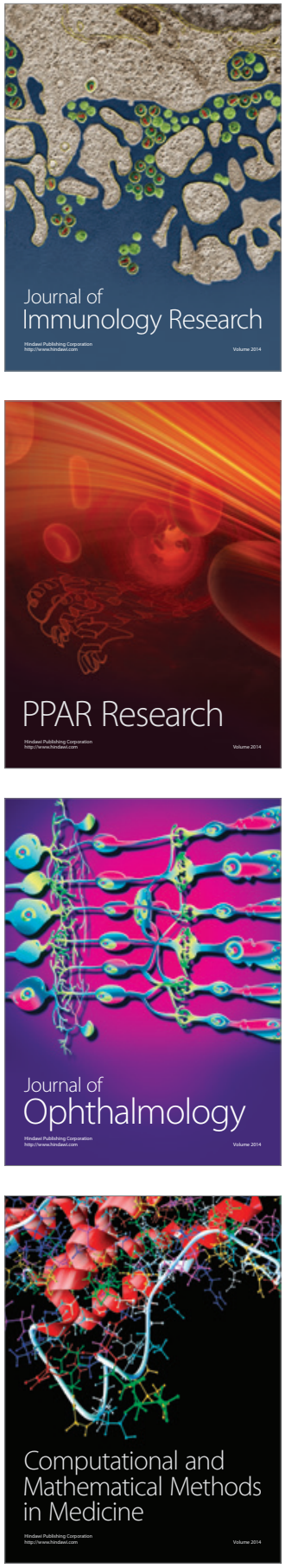

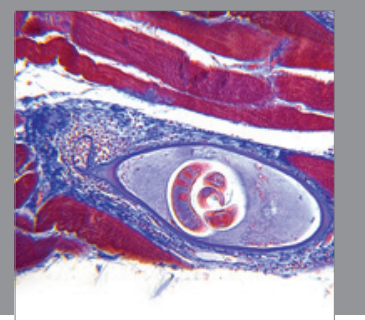

Gastroenterology

Research and Practice
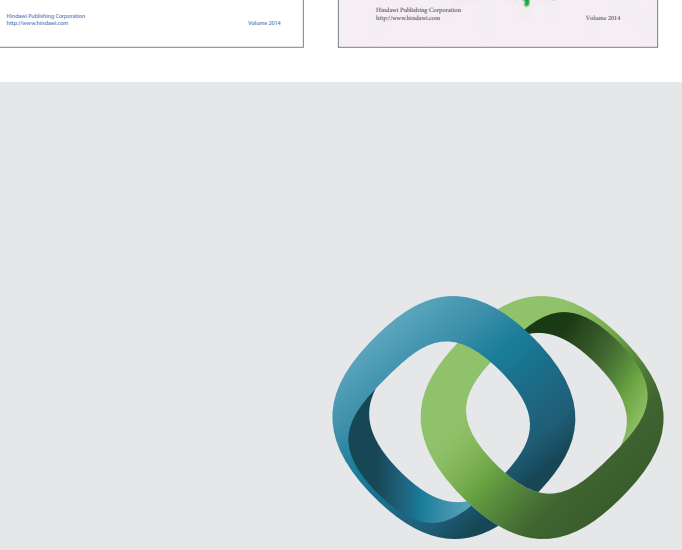

\section{Hindawi}

Submit your manuscripts at

http://www.hindawi.com
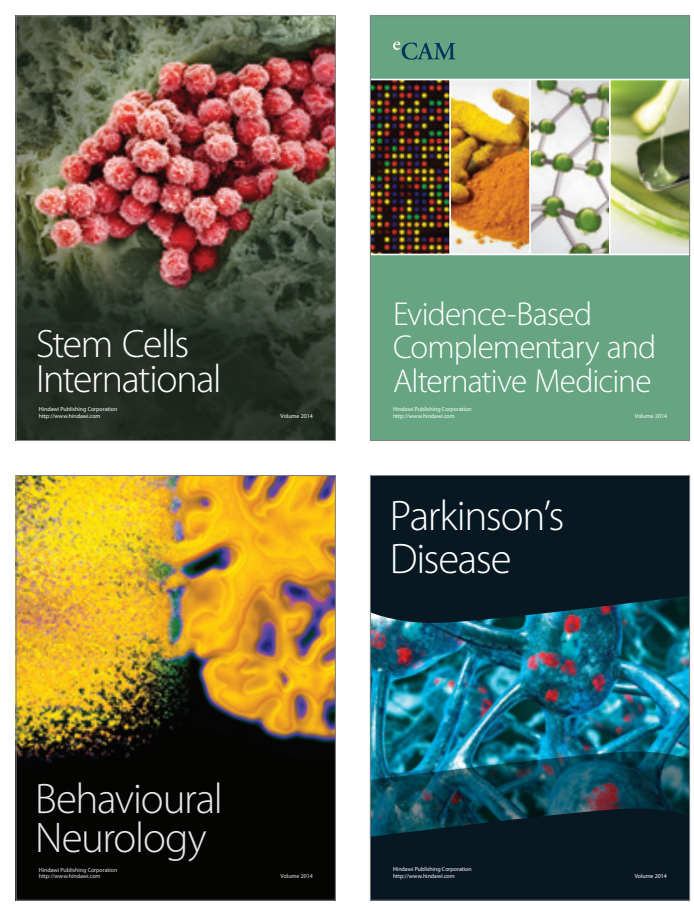

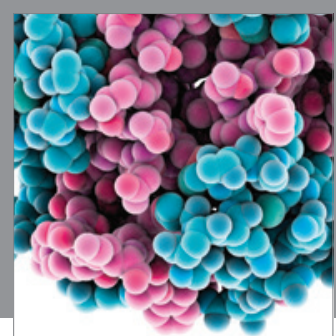

Journal of
Diabetes Research

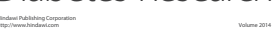

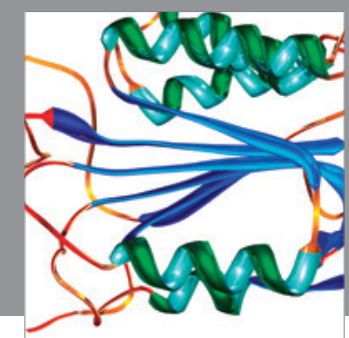

Disease Markers
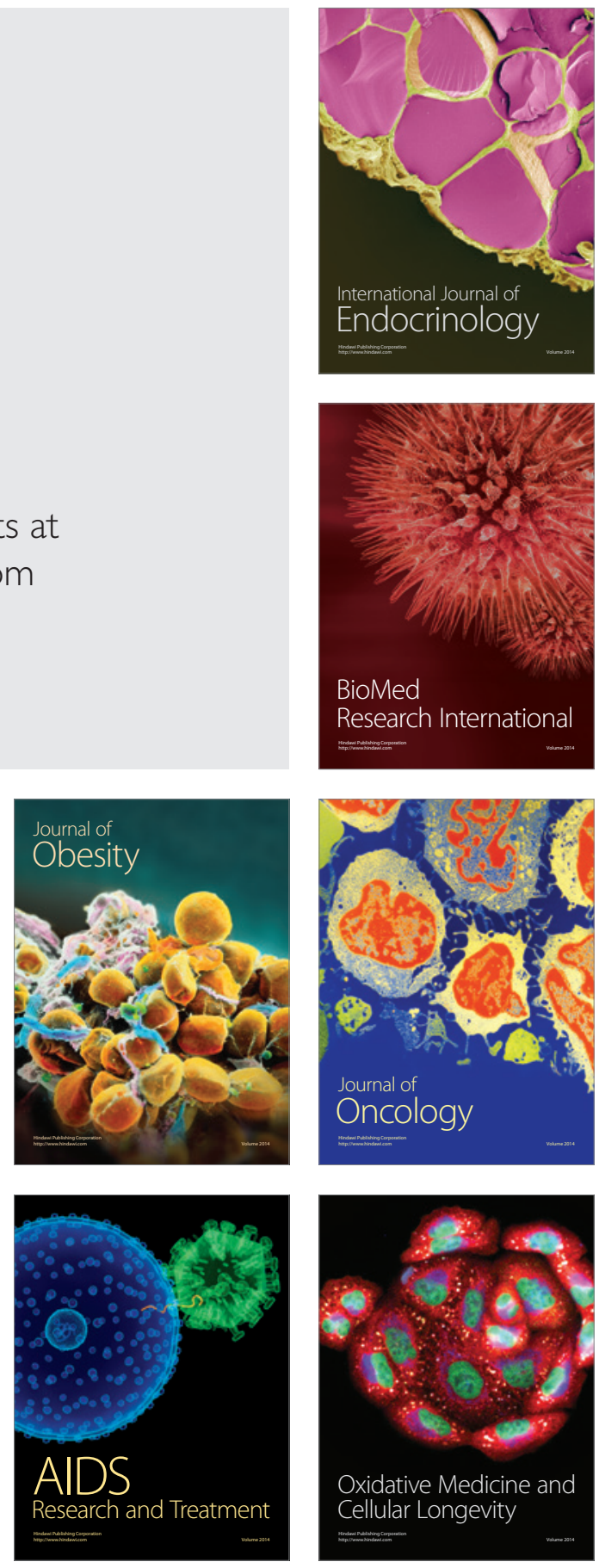